\title{
Membrane-Based Therapeutic Plasma Exchange in Intensive Care
}

\author{
Sebastien Redant ${ }^{a}$ David De Bels ${ }^{a}$ Khalid Ismailib Patrick M. Honoré ${ }^{a}$ \\ aDepartment of Intensive Care, Brugmann University Hospital, Université Libre de Bruxelles (ULB), Bruxelles,

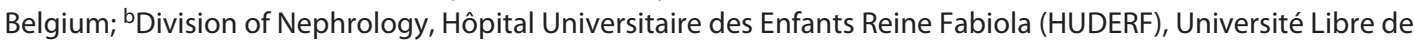 \\ Bruxelles (ULB), Bruxelles, Belgium
}

\section{Keywords}

Therapeutic plasma exchange - Thrombotic thrombocytopenic purpura - Acute liver failure - GuillainBarré syndrome - Antineutrophil cytoplasmic antibodyassociated vasculitis

\section{Abstract}

The principles and use of plasmapheresis are often little understood by intensivists. We propose to review the principles, the main indications, and the methods of using this technique.

(c) 2020 S. Karger AG, Basel

\section{Introduction}

The evolution of the understanding of the molecular mechanisms of several pathologies has allowed the expansion of therapeutic plasma exchange (TPE) indications. The general principle is to remove a circulating molecule from the blood in the hope of improving the clinical condition of the patient [1]. In contrast to hemodialysis, TPE preferentially removes high-molecularweight substances such as autoantibodies, antigen-anti- body complexes, and paraprotein immunoglobulin [2]. Two different plasma separation techniques exist: centrifugal separation (cTPE) and membrane separation (mTPE). The 2 techniques use different physical principles, but both are capable of effectively separating plasma substances from whole blood and delivering replacement with plasma or albumin [2]. We reviewed the principles, modalities, and different indications of this technique (Fig. 1).

\section{Principles of Centrifugal Separation}

The first therapeutic application of this technique dates back to the 1960s [3]. Blood flows from the patient to a centrifuge, with citrate anticoagulation introduced before centrifugation, and the blood elements return to the patient with a replacement fluid such as albumin or plasma after the centrifugation [2]. In CTPE, the centripetal force from rotation of a blood chamber at a speed of $2,000-2,500 \mathrm{rpm}$ is used to separate the blood components based on differences in density $[2,4,5]$. This ability to separate blood elements is useful as a treatment (via plasma exchange (PE) and/or blood component removal) for a range of pathologies and also as a means of collection (e.g., peripheral blood stem cells) or processing (e.g., bone marrow for transplant) [4]. karger@karger.com

(c) 2020 S. Karger AG, Basel

www.karger.com/bpu

Karger ${ }^{\prime}=$
Sebastien Redant

ICU Department, Brugmann University Hospital

4 Place Arthur Van Gehuchten

BE-1020 Brussels (Belgium)

Sebastien.Redant@CHU-Brugmann.be 
Fig. 1. Representation of a plasmapheresis membrane with the cellular elements of the blood and plasma constituents.

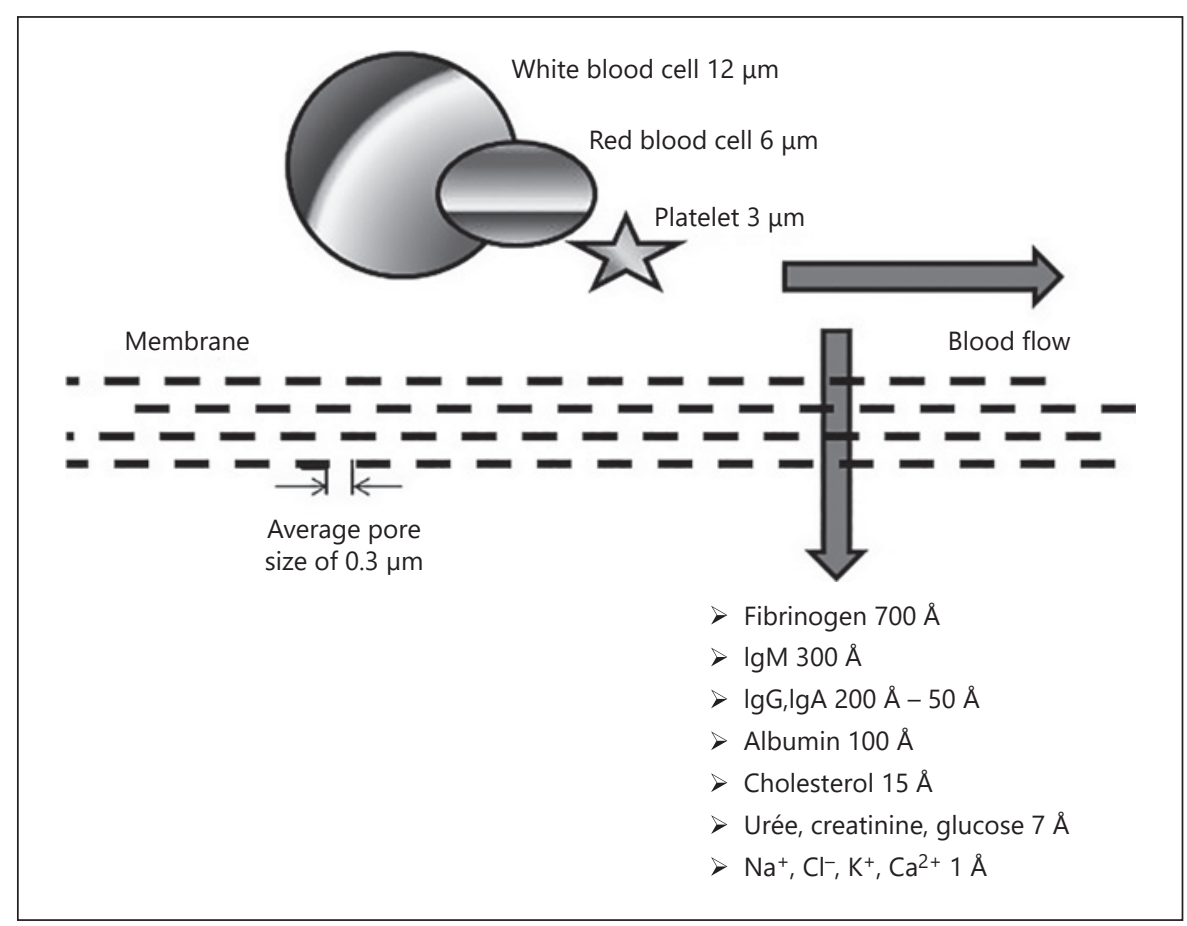

\section{Principles of Membrane Separation}

The first difference when compared with cTPE is that mTPE cannot perform cytapheresis [2]. The plasma separator membranes resemble a continuous dialysis procedure operating in ultrafiltration mode only [2]. The plasma containing the pathological element is ultrafiltered and then replaced by plasma or albumin [2]. In order to avoid filter clogging, it is necessary to limit the filtration fraction to $30-35 \%$ of the plasma [2]. The pores of $\mathrm{mTPE}$ membranes are larger than those in conventional hemofiltration membranes, allowing for the removal of macromolecules (proteins and lipoproteins), while leaving behind cellular components [5]. The membrane used is nonselective and removes the beneficial as well as the pathological constituents of the plasma [2].

Compared to the membrane system, PE by centrifugation is often more cumbersome and complicated. Centrifugation has the disadvantage of contamination of the plasma by the elements of the blood. The membrane technique is similar to hemofiltration and allows plasma to pass through pores, leaving platelets and other cellular elements in the blood. In addition, this technique is simpler, less expensive, and more reliable [1].

\section{Specificity of the Membranes}

Currently, only 2 membranes are approved by the FDA for mTPE in the USA [1]. The first is the Plasmaflo
OP filter (Asahi Medical, Tokyo, Japan), which is compatible with continuous renal replacement therapy machines. The second is the Prismaflex TPE set (Gambro Renal Products, Lakewood, CO, USA) (Table 1). Continuous renal replacement therapy machines which contain 2 pumps to simultaneously hemofilter and reinject the replacement fluid are best suited for MTPE [1]. The main disadvantage of mTPE is the inability to perform cytapheresis, meaning that in order for an institution to provide a range of apheresis therapies and cell collection services, a cTPE system must also be available [1]. The typical mTPE filter has a structure like a sponge with openings of different sizes [1]. These pores vary in size from 0.2 to $0.5 \mu \mathrm{m}$ with an average of $0.3 \mu \mathrm{m}$ [1]. In comparison, the size of platelets and red blood cells is between 2 and $3 \mu \mathrm{m}$, which corresponds to 10 times the size of a pore. Albumin measures $0.01 \mu \mathrm{m}$, which is 30 times smaller than a pore and passes easily through the membrane, as do $\operatorname{IgM}(0.03 \mu \mathrm{m})$ and cryoglobulins $(0.1 \mu \mathrm{m})$ [1].

\section{Indications for TPE}

The American Society for Apheresis (ASFA) publishes regularly updated guidelines regarding plasmapheresis indications, categorized according to their degree of evi- 
Table 1. Different membranes approved in the USA

\begin{tabular}{|c|c|c|c|c|c|}
\hline & Polymer & $\begin{array}{l}\text { Effective } \\
\text { surface area, } \mathrm{m}^{2}\end{array}$ & $\begin{array}{l}\text { Pore size, } \\
\mu \mathrm{m}\end{array}$ & Maximum TMP & SC data \\
\hline Plasmaflo $^{\mathrm{TM}}$ & Polyethylene & 0.5 & 0.3 & $100 \mathrm{~mm} \mathrm{Hg}$ & $\begin{array}{l}\text { Albumin } 0.99 \\
\text { IgG } 0.99 \\
\text { IgA } 1.0 \\
\text { IgM } 1.0 \\
\text { TotProtein } 1.0 \\
\text { TotCholesterol } 1.0\end{array}$ \\
\hline Prismaflex ${ }^{\circledR}$ & Polypropylene & 0.35 & l & $\begin{array}{l}100 \mathrm{~mm} \mathrm{Hg}(\mathrm{Qb}=50 \mathrm{~mL} / \mathrm{min}) \\
140 \mathrm{~mm} \mathrm{Hg}(\mathrm{Qb}=100 \mathrm{~mL} / \mathrm{min}) \\
190 \mathrm{~mm} \mathrm{Hg}(\mathrm{Qb}=180 \mathrm{~mL} / \mathrm{min})\end{array}$ & $\begin{array}{l}\text { Albumin } 0.97 \\
\text { IgG } 1.0 \\
\text { Apolipoprotein B } 0.95 \\
\text { IgM } 0.92\end{array}$ \\
\hline
\end{tabular}

dence $[1,6]$. Category I represents diseases for which TPE is a first-line treatment (e.g., Guillain-Barré syndrome [GBS]). Category II includes pathologies for which TPE is accepted as second-line (e.g., acute disseminated encephalomyelitis after steroid failure) therapy. Category III are indications that are not established and are considered on a case-by-case basis (e.g., IgA nephropathy), and category IV are the indications where the literature has proven no benefit or has shown deleterious effects $[1,6]$. Four recommendations of TPE have a level of evidence I grade $1 \mathrm{~A}$ and illustrate the principles of TPE: thrombotic thrombocytopenic purpura (TTP), acute liver failure, GBS, and antineutrophil cytoplasmic antibody (ANCA)associated vasculitis (AAV) (Table 2).

\section{Thrombotic Thrombocytopenic Purpura}

The acquired form of TTP is an entity caused by the presence of autoantibodies against a disintegrin-like and metalloprotease with thrombospondin type 1 motif, member 13 (ADAMTS13). The low activity of this protease leads to the accumulation of von Willebrand factor multimers with platelet-rich clot formation and occlusion of arterioles, often with renal failure and/or neurological involvement $[2,7]$. TPE is the cornerstone of treatment. Treatment failure is associated with a delay in the initiation of PE treatment, as well as the presence of coma or elevated Cr levels [7]. A randomized controlled study in 102 patients showed that PE was superior to plasma infusion alone in terms of platelet count increase, hospital mortality, and 6-month mortality [8]. This phenomenon is explained by an additive effect of both autoantibody removal and an increase in the amount of ADAMTS13 provided by the exchanged plasma [9].
TPE is started at a dose of 1.5 times the plasma volume (PV, $60 \mathrm{~mL} / \mathrm{kg}$ ), once daily. After confirmation of the diagnosis, the dose of $1.5 \times \mathrm{PV}$ is continued for 3 days as per the Canadian Apheresis Study Group [8], followed by a maintenance dose of $1.0 \times \mathrm{PV}$ [10]. This dose is maintained until signs of organ involvement - cerebral manifestations, renal failure, elevation of troponin, and abdominal pain - have resolved [10]. The addition of rituximab has shown a benefit in terms of platelet recovery rate and prevention of recurrence [11] and is commonly used to treat refractory or relapsing TTP, although it can also be used as an adjunct to TPE in newly diagnosed TTP [6]. An intensive schedule of rituximab dosing on days 1, 4, 8, and 15 following relapse diagnosis (to account for the removal of rituximab by TPE) has shown improved outcomes [11]. In refractory patients, twice-daily TPE in conjunction with rituximab has shown promise [12]. Various immunosuppressant agents and splenectomy can be considered in severe refractory cases [6]. TPE is discontinued when the platelet count exceeds $150 \times 10^{9} / \mathrm{L}$ and the lactate dehydrogenase level is near normal for at least 2 days [6].

Regarding the type of plasma used, it has been reported that the plasma cryosupernatant, which is depleted of high-molecular-weight von Willebrand factor multimers, may be more effective than fresh frozen plasma (FFP) [13]. However, a more recent study did not show superiority of 1 type of plasma over another [14].

\section{Acute Liver Failure}

In acute liver failure, TPE can remove albumin-bound toxins as well as unbound toxins, including aromatic amino acids, ammonia, endotoxin, indols, mercaptans, phe- 
Table 2. Category I recommendations for therapeutic apheresis

\begin{tabular}{|c|c|c|}
\hline & Indication & Grade \\
\hline Acute inflammatory demyelinating polyradiculoneuropathy/GBS & Primary & $1 \mathrm{~A}$ \\
\hline Acute liver failure & & $1 \mathrm{~A}$ \\
\hline Goodpasture & $\begin{array}{l}\text { Diffuse alveolar hemorrhage } \\
\text { Dialysis independence }\end{array}$ & $\begin{array}{l}1 \mathrm{C} \\
1 \mathrm{~B}\end{array}$ \\
\hline Chronic inflammatory demyelinating polyradiculoneuropathy & & $1 \mathrm{~B}$ \\
\hline Dilated cardiomyopathy idiopathic & NYHA II-IV & 1B \\
\hline Familial hypercholesterolemia & Homozygote & $1 \mathrm{~B}$ \\
\hline Focal segmental glomerulosclerosis & Recurrent in transplanted kidney & $1 \mathrm{~B}$ \\
\hline GVHD & Acute & $1 \mathrm{C}$ \\
\hline Hereditary hemochromatosis & & $1 \mathrm{~B}$ \\
\hline Hypertriglyceridemic pancreatitis & Severe & $1 \mathrm{C}$ \\
\hline Hyperviscosity in monoclonal gammopathies & $\begin{array}{l}\text { Synptomatic } \\
\text { Prophylaxis for rituximab }\end{array}$ & $1 \mathrm{~B}$ \\
\hline Liver transplantation & Desensitization, ABOi LD & $1 \mathrm{C}$ \\
\hline Myasthenia gravis & Acute & $1 \mathrm{~B}$ \\
\hline $\mathrm{N}$-methyl d-aspartate receptor antibody encephalitis & & $1 \mathrm{C}$ \\
\hline Paraproteinic demyelinating neuropathies & $\begin{array}{l}\text { IgG, IgA } \\
\text { IgM }\end{array}$ & $1 \mathrm{~B}$ \\
\hline $\begin{array}{l}\text { Progressive multifocal leukoencephalopathy associated with } \\
\text { natalizumab }\end{array}$ & & $1 \mathrm{C}$ \\
\hline Renal transplantation $\mathrm{ABO}$ incompatible & Desensitization, LD & $1 \mathrm{~B}$ \\
\hline Thrombotic microangiopathy complement mediated & Factor $\mathrm{H}$ autoantibodies & $2 \mathrm{C}$ \\
\hline Thrombotic microangiopathy drug associated & Ticlopidine & $2 \mathrm{~B}$ \\
\hline TTP & & $1 \mathrm{~A}$ \\
\hline AAV & MPA/GPA/RLV:RPGN, Cr $>5.7$ & $1 \mathrm{~A}$ \\
\hline Wilson's disease fulminant & Fulminant & $1 \mathrm{C}$ \\
\hline \multicolumn{3}{|c|}{$\begin{array}{l}\text { AAV, antineutrophil cytoplasmic antibody-associated vasculitis; GBS, Guillain-Barré syndrome; GVHD, } \\
\text { graft-versus-host disease; TTP, thrombotic thrombocytopenic purpura; MPA, microscopic polyangiitis; GPA, } \\
\text { granulomatosis with polyangiitis; RLV, renal-limited vasculitis; RPGN, rapidly progressive glomerulonephritis; } \\
\text { LD, living donor; NYHA, New York Heart Association. }\end{array}$} \\
\hline
\end{tabular}

nols, and other factors that may be responsible for hepatic coma, hyperkinetic syndrome, and decreased systemic vascular resistance and cerebral blood flow. The removal of inflammatory mediators seems to play a role in the treatment of acute liver failure. Several studies show improved cerebral blood flow, mean arterial pressure, cerebral perfusion pressure, cerebral metabolic rate, and increased hepatic blood flow and improvements in other laboratory parameters such as cholinesterase activity or galactose elimination capacity [6]. Different purification systems exist, among them PE. PE is a simple technique but not devoid of side effects. It may be accompanied by hypernatremia, metabolic alkalosis, citrate intoxication, and abrupt changes in oncotic pressure. In Japan, where the Molecular Adsorbent Recirculating System (MARS) is not in use, Nakae et al. [15] developed a 
combination of PE therapy and continuous diafiltration: plasma diafiltration (PDF). PDF is a blood purification therapy in which PE is performed using a plasma membrane separator, while the dialysate flows outside of the plasma separator and hemodiafiltration is performed simultaneously.

There are several case series of patients with acute hepatic insufficiency and fulminant hepatitis who underwent this technique using a membrane plasma separator (Evacure EC-2A plasma separator; Kuraray, Tokyo, Japan) $[8,16-19]$. They observed a significant decrease in total bilirubin, interleukin-18 (IL-18), cystatin C, and citrate. IL-18 is a protein of molecular weight $18.5 \mathrm{kDa}$ that is produced by activated macrophages, particularly in liver Kupffer cells [20], and leads to hyperproduction of TNF-alpha and other pro-inflammatory cytokines. Cystatin $\mathrm{C}$ is a marker of glomerular lesions unrelated to muscle mass, age, or sex [21].

The plasma separator used in their case series had a pore size of $0.01 \mu \mathrm{m}$, which is smaller than that of the conventional plasmapheresis membrane $(0.2-0.4 \mu \mathrm{m})$. This membrane has a sieving coefficient of 0.3 for albumin and can extract small- to medium-molecular-weight molecules with preservation of coagulation factors [15]. One of the benefits of PDF is better control of citrate, first because the system uses less plasma and therefore less citrate and also because the citrate is eliminated by hemodiafiltration.

Given that conventional PDF is performed intermittently over a period of $8 \mathrm{~h}$ and can result in hemodynamic instability, continuous PDF has been proposed as an alternative [22]. Continuous PDF uses the same membrane EC-2A plasma separator with the following parameters: blood flow rate of $80 \mathrm{~mL} / \mathrm{min}$, dialysate flow rate of $400 \mathrm{~mL} / \mathrm{h}$, and replacement flow rate of $280 \mathrm{~mL} / \mathrm{h}$ with FFP infused at $120 \mathrm{~mL} / \mathrm{h}$. This treatment regimen resulted in a significant fall in the Model for End-Stage Liver Disease (MELD) score from 34.5 to $28.0(p=0.005)$ and bilirubin from 10.9 to $7.25(p=0.048)$ and a tendency to decrease the INR of $1.89-1.31(p=0.084)$. The SOFA score went from 10.0 to $7.5(p<0.039)$. These techniques are especially useful in areas of the world where liver transplantation is less common [22].

High-volume plasmapheresis (HVP) is another technique for which improved outcomes have been reported in patients with acute liver failure [23]. In a prospective randomized multicenter study of 183 patients over a 13year period, standard medical therapy (SMT) combined with HVP (15\% ideal body weight [ 8-12 L FFP] over 9 $\mathrm{h})$, as compared to SMT alone, resulted in a significant increase in hospital survival, including in patients who refused liver transplantation due to contraindications (comorbidity and psychiatric pathologies) [23]. The main criticism addressed to this study was that SMT may have changed during the extended patient enrollment period (13 years), potentially influencing the results. However, the authors note that SMT was identical in both the treatment and control groups, and a midterm analysis demonstrated the same trend $[24,25]$. While HVP is not an extracorporeal liver support therapy, it simulates some aspects of such support by removing toxic metabolites, replacing potentially beneficial factors, correcting coagulopathy and removing mediators of multiorgan failure (pro-inflammatory cytokines and damage-associated molecular patterns) $[24,26]$.

Another study by Yue-Meng et al. [27] showed survival benefit in chronic hepatitis B patients with hepatic decompensation and acute-on-chronic liver failure (ACLF) who were treated with PE in combination with entecavir. The cumulative survival rate at weeks 4 and 12 in the PE group and the control group was, respectively, 37 and $18 \%$, and 29 and $14 \%(p<0.001)$ [27].

A prospective observational study of 54 patients with ACLF secondary to hepatitis B examined the issue of potential citrate accumulation due to PE-centered therapy without concomitant filtration or dialysis [28]. The ratio of total to ionized calcium $\left(\mathrm{Ca}_{\text {tot }} / \mathrm{Ca}_{\text {ion }}\right)$ was used as an indicator of citrate accumulation. The mean $\mathrm{Ca}_{\text {tot }} / \mathrm{Ca}_{\text {ion }}$ was $2.05 \pm 0.14$ prior to $\mathrm{PE}$ and was elevated in all patients immediately following PE $(4.34 \pm 1.52)$, but decreased within $1 \mathrm{~h}$ after $\mathrm{PE}(2.36 \pm 0.32)$ and returned to baseline by the following morning $(2.10 \pm 0.14)$. The main metabolic abnormalities encountered were asymptomatic hypocalcemia and mild metabolic alkalosis. The authors concluded that citrate accumulation is well-tolerated by patients with ACLF in this setting [28].

\section{Guillain-Barré Syndrome}

The rationale for the use of TPE in GBS is the presence of an autoantibody directed against peripheral nerve myelin [6]. Several randomized controlled trials have shown a net benefit of using TPE versus supportive treatment alone in GBS management $[29,30]$. TPE accelerates motor recovery and decreases mechanical ventilation time [30]. The Cochrane Neuromuscular Disease Group reviewed the use of TPE in GBS and recommended that TPE is an effective treatment in both mild and severe forms of GBS and should be initiated within 7 days of the onset of the disease $[6,31]$. The sequential combination of intravenous immunoglobulin (IVIG) and TPE does not offer any benefit and is not 
recommended. There are insufficient data to recommend TPE after IVIG treatment failure [6]. Caution should be exercised in these patients, as they may have autonomic dysfunction and therefore be sensitive to fluid shifts occurring during treatment. Up to $10 \%$ of patients may experience a relapse and require additional TPE [6].

\section{ANCA-Associated Vasculitis}

$\mathrm{AAV}$ is defined as necrotizing vasculitis predominantly in small vessels with little or no immune deposition [6]. ANCA can be specific for myeloperoxidase or proteinase 3 and is clinically divided into microscopic polyangiitis, granulomatosis with polyangiitis, and renal-limited vasculitis [6]. AAV can affect all organs but in particular the kidney ( $70 \%$ of the cases) in the form of rapidly progressive glomerulonephritis with a high risk of ESRD [6].

The presence of ANCAs is the rationale for the use of TPE in AAV. The characteristic lesion is vessel wall necrosis with release of plasma components and activation of coagulation [6]. Before the emergence of a precise classification of AAVs, various studies examined the utility of TPE in AAV via investigation of its use in the treatment of rapidly progressive glomerulonephritis, a clinical entity that is not exclusive to AAV [6]. A meta-analysis of those studies concluded that TPE can reduce the endpoint of ESRD and death, and the use of TPE was recommended in patients with severely impaired renal function defined by a serum Cr level above $5.7 \mathrm{mg} / \mathrm{dL}$ or the requirement of dialysis [6, 32].

In patients with AAV presenting with diffuse alveolar hemorrhage, TPE has weaker evidence. A retrospective study reported a reduction in all-cause in-hospital mortality in patients who received TPE as compared to those who did not ( 35.6 vs. $54.2 \%, p=0.041$ ), but did not reach statistical significance in the multivariate logistic regression analysis of propensity-matched patients [33]. Furthermore, the median duration of hospitalization was longer (44 [27-84] vs. 30 [16-58] days, $p=0.027$ ) for the PE group.

In the MEPEX study, 137 patients with a new diagnosis of AAV confirmed by renal biopsy and who had a Cr level $>500 \mu \mathrm{mol} / \mathrm{L}(5.8 \mathrm{mg} / \mathrm{dL})$ were randomized to receive either 7 PEs $(n=70)$ or $3,000 \mathrm{mg}$ intravenous methylprednisolone $(1,000 \mathrm{mg} /$ day $\times 3)$ [34]. A significant difference was reported in the number of patients independent from dialysis at 3 months (69\% in the TPE group vs. $49 \%$ in the methylprednisolone group, $p=0.02$ ), while the survival rate and severe adverse event rates were similar [34].

The PEXIVAS study was a randomized controlled trial that compared standard versus low-dose glucocorticoids, with or without TPE, in a cohort of 704 patients recruited from 98 sites in 15 countries [32]. Patients were followed up for up to 7 years for the primary outcome of death of any cause or end-stage kidney disease. This study did not show a benefit of TPE in the first year. The use of TPE did not reduce the incidence of death or end-stage kidney disease in the overall analysis [32]. In the study, TPE consisted of 7 exchanges of $60 \mathrm{~mL} / \mathrm{kg}$ over 14 days. Some patients require up to 12 PEs to achieve an improvement in renal function [35].

\section{Plasmapheresis in COVID-19}

Coronavirus disease 2019 (COVID-19) is a viral infectious disease caused by SARS-CoV-2 and is currently a World Health Organization (WHO)-declared pandemic. COVID-19 is increasingly well described and results from a complex interaction of cytokine storm, inflammation, endothelial dysfunction, and pathological coagulation [36]. A case report has been published of a 50 -year-old patient with severe COVID-19 who was successfully treated with 4 sessions of plasmapheresis with $6,000 \mathrm{~mL}$ of plasma followed by $20 \mathrm{~g}$ of IVIG [37]. The use of TPE in severe COVID-19 patients has been associated with higher extubation rate and lower 14- and 28-day mortality [38]. PE may provide benefit by removing inflammatory cytokines, stabilizing endothelial membranes, resetting the hypercoagulable state, and decreasing viral load $[36,37]$. SARS-CoV-2 has a diameter of 60-140 nm, also large enough to be eliminated with double filtration plasmapheresis [39].

\section{Using Plasmapheresis}

Dose

The usual dose of plasmapheresis is equivalent to 1.2 times the circulating PV (range 1.0-1.5). This range corresponds to the removal of $63-72 \%$ of the constituents of the plasma. The ratio between the extracted plasma constituents and the amount remaining in the plasma after TPE follows an exponential curve. Increasing the volume of plasma exchanged beyond 1.5 times the PV decreases very little the proportion of volume remaining. In addition, very often the pathogenic molecule extracted via TPE is also present in the interstitial fluid and slow transfer to the blood occurs after the end of the plasmapheresis session. This results in a late rebound effect, which explains the need for multiple sessions of TPE [40]. This is typical of diseases mediated by IgG antibodies $(146 \mathrm{kDa})$, of which only $30 \%$ are present in the intravascular compartment, as compared to IgM $(970 \mathrm{kDa})$, of which $90 \%$ is in the plasma. This explains why Waldenstrom's mac- 
roglobulinemia disease can be successfully treated with only 1-2 sessions of TPE.

\section{Anticoagulation}

Citrate is the anticoagulant of choice for the preservation of blood derivatives and for low-flow extracorporeal circulation circuits (typically $30-70 \mathrm{~mL} / \mathrm{min}$ ) when citrate loading can be managed by clearance mechanisms (e.g., dialysate flow rate) [41]. Citrate anticoagulation can be used safely with less risk of bleeding than heparin [42]. On the one hand, when citrate is used in CTPE, it is separated and discarded with the rest of the components. On the other hand, in $\mathrm{mTPE}$, it is possible that a large amount of citrate is delivered to the patient because of the small proportion extracted from the plasma [40].

\section{Replacement Fluids and Supplements}

When the replacement fluid is FFP, the citrate content of the FFP represents an additional load that the patient has to metabolize [40]. FFP replacement is universally used in TTP with the rationale of eliminating autoantibodies to ADAMTS13 and restoring ADAMTS13 protease activity [6].

TPE for indications other than TTP can be performed using 5\% albumin, provided that the serum albumin does not exceed $5 \mathrm{~g} / \mathrm{dL}$. This avoids the possible complications of FFP transfusions. If the albumin level increases too much, a $0.9 \% \mathrm{NaCl}$ infusion is used as a replacement fluid during the first quarter of the procedure at a rate $20 \%$ greater than the plasmapheresis withdrawal rate to compensate for the shift of saline serum to the interstitium [43, 44].

In repeated plasmapheresis with replacement with albumin and $0.9 \% \mathrm{NaCl}$, coagulation factors may fall. Fibrinogen levels taken at the beginning of the plasmapheresis procedure can be used to monitor this, and if the fibrinogen drops below $100 \mathrm{mg} / \mathrm{dL}$, the use of FFP for the last $500 \mathrm{~mL}$ of the replacement solution may be indicated [44].

\section{Safety and Efficacy}

Serious complications are rare: anaphylactoid reactions $0.25 \%$, cardiac $0.2 \%$, respiratory $0.2 \%$, and hemorrhage and infection $0.02 \%$. Transfusion-related acute lung injury is possible [39]. Allergic reactions may be prevented by the administration of an antihistamine such as diphenhydramine and an antipyretic such as acetaminophen (paracetamol) [6].

During laboratory first evaluation of the membrane, a sieving coefficient of 1.0 was found for all plasma components [44]. A prospective, randomized, paired, cross-over study involving 21 patients showed that the membrane

technique took $10.5 \%$ more time than the centrifugation technique. However, the end result in terms of the decrease in markers (e.g., IgM and IgG) was equivalent [45]. The additional time could pose a problem in centers that frequently perform consecutive plasmapheresis but is not likely to be an issue in intensive care where staff are more accustomed to hemofiltration systems and the use of plasmapheresis is occasional.

\section{Conclusion}

Plasmapheresis is a life-saving technique in some conditions and should be a part of the armamentarium of every intensivist.

\section{Acknowledgement}

We would like to thank Dr. Melissa Jackson for reviewing our article.

\section{Conflict of Interest Statement}

The authors declare to have no conflicts of interest.

\section{Funding Sources}

The authors did not receive any funding.

\section{Author Contributions}

S.R. and P.M.H. designed the study. All authors participated in drafting and reviewing. All authors read and approved the final version of the manuscript.

References

Blood Purif 2021;50:290-297 DOI: $10.1159 / 000510983$
1 Gashti CN. Membrane-based therapeutic plasma exchange: a new frontier for nephrologists. Semin Dial. 2016 Sep;29(5):382-90.

2 Williams ME, Balogun RA. Principles of separation: indications and therapeutic targets for plasma exchange. Clin J Am Soc Nephrol. 2014 Jan;9(1):181-90.

3 Schwab PJ, Fahey JL. Treatment of Waldenstrom's macroglobulinemia by plasmapheresis. N Engl J Med. 1960 Sep 22;263:574-9.

4 Wehrli G. Therapeutic apheresis instrumentation. J Clin Apher. 2011;26(5):286-90.

5 Gashti CN, Andreoli DC, Patel D. Membrane-based therapeutic plasma exchange (mTPE): technical and clinical experience. J Clin Apher. 2018 Feb;33(1):38-45. 
6 Padmanabhan A, Connelly-Smith L, Aqui N, Balogun RA, Klingel R, Meyer E, et al. Guidelines on the use of therapeutic apheresis in clinical practice: evidence-based approach from the writing committee of the American Society for apheresis: the eighth special issue. J Clin Apher. 2019 Jun;34(3):171-354.

7 Pereira A, Mazzara R, Monteagudo J, Sanz C, Puig L, Martínez A, et al. Thrombotic thrombocytopenic purpura/hemolytic uremic syndrome: a multivariate analysis of factors predicting the response to plasma exchange. Ann Hematol. 1995 Jun;70(6):319-23.

8 Rock GA, Shumak KH, Buskard NA, Blanchette VS, Kelton JG, Nair RC, et al. Comparison of plasma exchange with plasma infusion in the treatment of thrombotic thrombocytopenic purpura. Canadian Apheresis Study Group. N Engl J Med. 1991 Aug 8;325(6): 393-7.

9 Blombery P, Scully M. Management of thrombotic thrombocytopenic purpura: current perspectives. J Blood Med. 2014;5:15-23.

10 Joly BS, Coppo P, Veyradier A. Thrombotic thrombocytopenic purpura. Blood. 2017 May 25;129(21):2836-46.

11 Froissart A, Buffet M, Veyradier A, Poullin P, Provôt F, Malot S, et al. Efficacy and safety of first-line rituximab in severe, acquired thrombotic thrombocytopenic purpura with a suboptimal response to plasma exchange. Experience of the French Thrombotic Microangiopathies Reference Center. Crit Care Med. 2012 Jan;40(1):104-11.

12 Soucemarianadin M, Benhamou Y, Delmas Y, Pichereau C, Maury E, Pène F, et al. Twicedaily therapeutical plasma exchange-based salvage therapy in severe autoimmune thrombotic thrombocytopenic purpura: the French TMA Reference Center experience. Eur J Haematol. 2016 Aug;97(2):183-91.

13 Rock G, Shumak KH, Sutton DM, Buskard NA, Nair RC. Cryosupernatant as replacement fluid for plasma exchange in thrombotic thrombocytopenic purpura. Members of the Canadian Apheresis Group. Br J Haematol. 1996 Aug;94(2):383-6.

14 Toussaint-Hacquard M, Coppo P, Soudant M, Chevreux L, Mathieu-Nafissi S, Lecompte $\mathrm{T}$, et al. Type of plasma preparation used for plasma exchange and clinical outcome of adult patients with acquired idiopathic thrombotic thrombocytopenic purpura: a French retrospective multicenter cohort study. Transfusion. 2015 Oct;55(10):244551.

15 Nakae H, Igarashi T, Tajimi K. Selective plasma exchange with dialysis in patients with acute liver failure. Ther Apher Dial. 2012 Oct; 16(5):467-71.

16 Nakae H, Yonekawa C, Wada H, Asanuma Y, Sato T, Tanaka H. Effectiveness of combining plasma exchange and continuous hemodiafiltration (combined modality therapy in a parallel circuit) in the treatment of patients with acute hepatic failure. Ther Apher. 2001 Dec; $5(6): 471-5$
17 Nakae H, Asanuma Y, Tajimi K. Cytokine removal by plasma exchange with continuous hemodiafiltration in critically ill patients. Ther Apher. 2002 Dec;6(6):419-24.

18 Steiner C, Mitzner S. Experiences with MARS liver support therapy in liver failure: analysis of 176 patients of the International MARS Registry. Liver. 2002;22(Suppl 2):20-5.

19 Rifai K, Ernst T, Kretschmer U, Bahr MJ, Schneider A, Hafer C, et al. Prometheus: a new extracorporeal system for the treatment of liver failure. J Hepatol. 2003 Dec;39(6): 984-90.

20 Okamura H, Tsutsi H, Komatsu T, Yutsudo M, Hakura A, Tanimoto T, et al. Cloning of a new cytokine that induces IFN-gamma production by T cells. Nature. 1995 Nov 2; 378(6552):88-91.

21 Newman DJ. Cystatin C. Ann Clin Biochem. 2002 Mar;39(Pt 2):89-104.

22 Komura T, Taniguchi T, Sakai Y, Yamashita T, Mizukoshi E, Noda T, et al. Efficacy of continuous plasma diafiltration therapy in critical patients with acute liver failure. J Gastroenterol Hepatol. 2014 Apr;29(4):782-6.

23 Larsen FS, Schmidt LE, Bernsmeier C, Rasmussen A, Isoniemi H, Patel VC, et al. Highvolume plasma exchange in patients with acute liver failure: an open randomised controlled trial. J Hepatol. 2016 Jan;64(1):69-78

24 Karvellas CJ, Stravitz RT. High volume plasma exchange in acute liver failure: dampening the inflammatory cascade? J Hepatol. 2016 Jan;64(1):10-2.

25 Larsen FS. Reply to: "High volume plasma exchange in patients with acute liver failure." J Hepatol. 2016 Sep;65(3):647-8.

26 Maiwall R, Moreau R. Plasma exchange for acute on chronic liver failure: is there a light at the end of the tunnel? Hepatol Int. 2016 May;10(3):387-9.

27 Yue-Meng W, Yang LH, Yang JH, Xu Y, Yang J, Song GB. The effect of plasma exchange on entecavir-treated chronic hepatitis B patients with hepatic de-compensation and acute-onchronic liver failure. Hepatol Int. 2016 May; 10(3):462-9.

28 Ma Y, Xu Y, Chen F, Wang Y, Bai L, Tang H. Good tolerance of citrate accumulation due to plasma exchange among patients with acuteon-chronic liver failure: a prospective, observational study. Can J Gastroenterol Hepatol. 2018;2018:4909742.

29 Osterman PO, Fagius J, Lundemo G, Pihlstedt P, Pirskanen R, Sidén A, et al. Beneficial effects of plasma exchange in acute inflammatory polyradiculoneuropathy. Lancet. 1984 Dec 8;2(8415):1296-9.

30 Efficiency of plasma exchange in GuillainBarre syndrome: role of replacement fluids. French Cooperative Group on Plasma Exchange in Guillain-Barre syndrome. Ann Neurol. 1987 Dec;22(6):753-61.

31 Chevret S, Hughes RA, Annane D. Plasma exchange for Guillain-Barré syndrome. Cochrane Database Syst Rev. 2017 Feb 27;2(2): CD001798.
32 Walsh M, Merkel PA, Peh CA, Szpirt WM, Puechal X, Fujimoto S, et al. Plasma exchange and glucocorticoids in severe ANCA-associated vasculitis. N Engl J Med. 2020 Feb 13; 382(7):622-31.

33 Uechi E, Okada M, Fushimi K. Effect of plasma exchange on in-hospital mortality in patients with pulmonary hemorrhage secondary to antineutrophil cytoplasmic antibody-associated vasculitis: a propensity-matched analysis using a nationwide administrative database. PLoS One. 2018;13(4):e0196009.

34 Jayne DR, Gaskin G, Rasmussen N, Abramowicz D, Ferrario F, Guillevin L, et al. Randomized trial of plasma exchange or high-dosage methylprednisolone as adjunctive therapy for severe renal vasculitis. J Am Soc Nephrol. 2007 Jul;18(7):2180-8.

35 de Luna G, Chauveau D, Aniort J, Carron PL, Gobert P, Karras A, et al. Plasma exchanges for the treatment of severe systemic necrotizing vasculitides in clinical daily practice: data from the French Vasculitis Study Group. J Autoimmun. 2015 Dec;65:49-55.

36 Keith P, Day M, Perkins L, Moyer L, Hewitt $\mathrm{K}$, Wells A. A novel treatment approach to the novel coronavirus: an argument for the use of therapeutic plasma exchange for fulminant COVID-19. Crit Care. 2020;24(1):128.

37 Shi H, Zhou C, He P, Huang S, Duan Y, Wang X, et al. Successful treatment with plasma exchange followed by intravenous immunoglobulin in a critically ill patient with COVID-19. Int J Antimicrob Agents. 2020 Apr 13;56(2):105974.

38 Khamis F, Al-Zakwani I, Al Hashmi S, Al Dowaiki S, Al Bahrani M, Pandak N, et al. Therapeutic plasma exchange in adults with severe COVID-19 infection. Int J Infect Dis. 2020 Jun 23;99:214-8.

39 Turgutkaya A, Yavaşoğlu İ, Bolaman Z. Application of plasmapheresis for Covid-19 patients. Ther Apher Dial. 2020.

40 Ward DM. Conventional apheresis therapies: a review. J Clin Apher. 2011;26(5):230-8.

41 Lee G, Arepally GM. Anticoagulation techniques in apheresis: from heparin to citrate and beyond. J Clin Apher. 2012;27(3):117-25.

42 Betjes MG, van Oosterom D, van Agteren M, van de Wetering J. Regional citrate versus heparin anticoagulation during venovenous hemofiltration in patients at low risk for bleeding: similar hemofilter survival but significantly less bleeding. J Nephrol. 2007 SepOct;20(5):602-8.

43 Mokrzycki MH, Balogun RA. Therapeutic apheresis: a review of complications and recommendations for prevention and management. J Clin Apher. 2011;26(5):243-8.

44 Grossman L, Benny WB, Buchanan J, Erickson RR, Buffaloe GW. Clinical evaluation of a flat-plate membrane plasma exchange system. J Clin Apher. 1983;1(4):225-37.

45 Golla P, Hafer C, Clajus C, Schmidt BMW, Kielstein J. Membrane versus centrifuge based therapeutic plasma exchange: a clinical crossover comparison (Abstract). NDT-Plus. 2011;4:3. 